\section{Math in the Time of Plague}

\section{BarRy Mazur}

The Viewpoint column offers readers of the

Mathematical Intelligencer the opportunity to write

about any issue of interest to the international

mathematical community. Disagreement and

controversy are welcome. The views and opinions

expressed here, however, are exclusively those of the

author. The publisher and editors-in-chief do not

endorse them or accept responsibility for them. Articles

for Viewpoint should be submitted to the editors-in-

chief. n times like the present-with microscopic hedgehogs of coronavirus short-circuiting our world like a swarm of locusts (Figure 1); disintegrating our communities; threatening our families; casting a shadow on the present for our elders, on the future for our youth; immobilizing our economy; and poised to challenge the springs and gears of our democracy-our thoughts have certainly changed in mood, if not in substance.

Today's (July 26, 2020) announced unemployment rate is a number I hesitate to write. It is proof enough that some of the less fortunate in our society are bearing the greater burden. One wonders whether this is a given in every plague; how many low-paid Egyptian laborers were collateral damage in the tenfold volley of altercation between God and Pharaoh?

To defy all this, we should be looking out for what we can do for the good of others, but also, we could be looking in, for some mode of consolation. Why don't we look about for gems of constancy-in our thoughts, expectations, in our ways of understanding the world-and rejoice in them-even the tiniest of them-as sparkles affirming the robustness of our souls?

Our daily missions have changed drastically: healers are at the front lines, as are those who provide equipment for them, as are many in the applied sciences-all of these now feeling the urgent responsibility, and hence the strain, to produce, and to produce rapidly, helpful things to deal with this crisis.

Parents (and grandparents) have become homeschool teachers. Being bound in the nutshell of one's own house and yet exploring, in companionship with a first-grader, a world of Mesozoic pterosaurs (a world entirely unknown to me until a week ago) is thrilling, even though any metaphoric connection to the equally unknown future of this world had best be kept at bay.

Our ways of coming together have been transformed: The theaters, of course, are shut down. As for performances, well, there are fixed stage-blocking readings of Shakespeare's plays, the actors in Zoom gallery view, such as Two Gentlemen of Verona with the byline "The Show Must Go OnLine." This follows good tradition, in that Shakespeare himself seemed to adapt well to the quarantine of plague after plague. ${ }^{1}$

Thankfully, there still is, there always is, music: the food-yes, of love-but also, perhaps now, of comfortperhaps of nostalgia. There are Yo-Yo Ma's wonderful Songs of Comfort amid global crisis, and Neapolitan neighborhoods singing in harmony, yet separated by their balconies. Or a performance of the serenade "Nessun

${ }^{1}$ In life, and in metaphor; see Stephen Greenblatt's striking "What Shakespeare Actually Wrote About the Plague," New Yorker, May 7, 2020. 


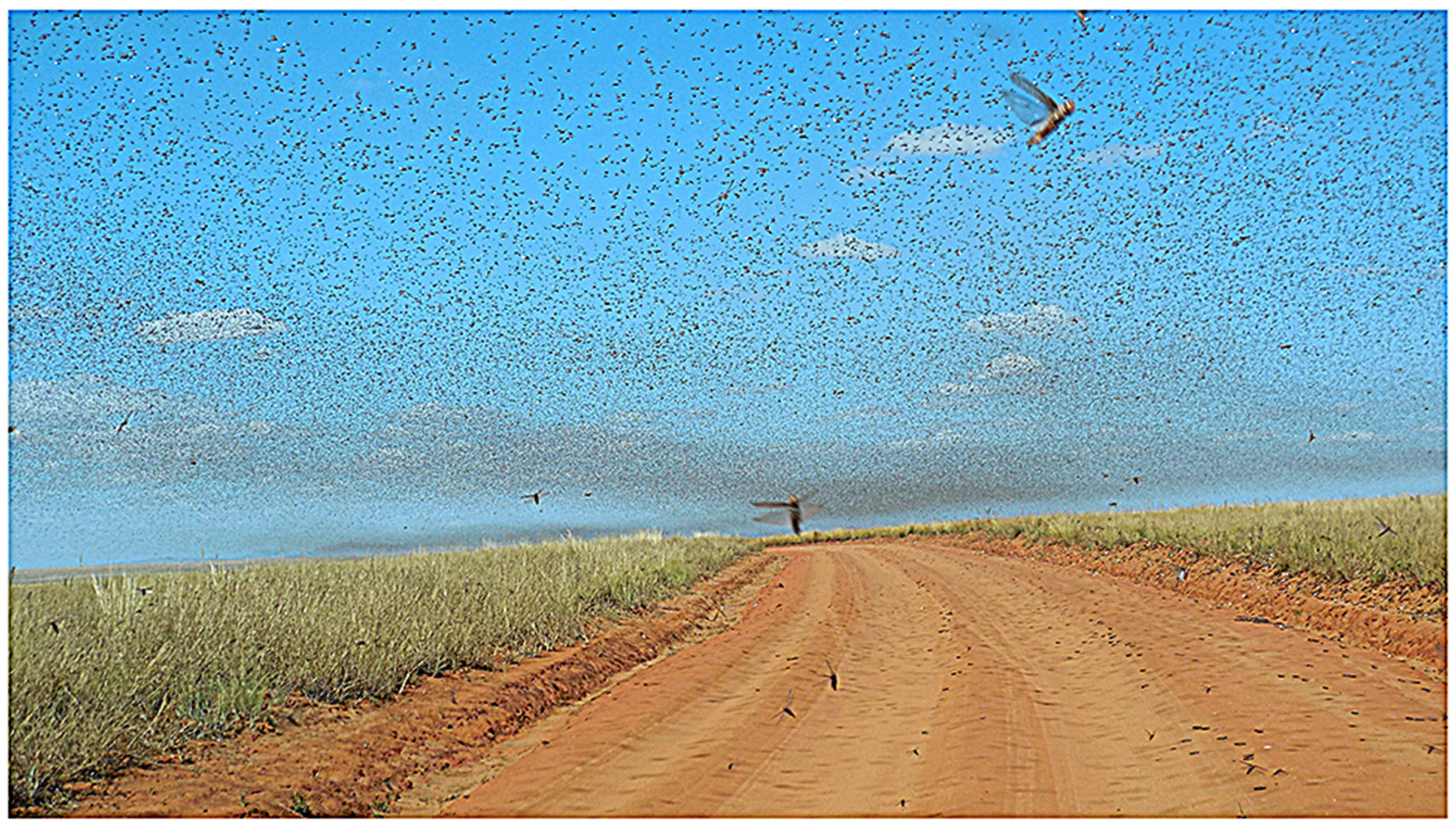

Figure I. Swarm of locusts near Satrokala, Madagascar. (Photograph by Iwoelbern, reproduced under a Creative Commons Share Alike license.)

Dorma" from Turandot to hospital workers in the courtyard of a Warsaw hospital. ${ }^{2}$

There will surely be art (of the traditional sort and, very likely, of novel forms as well) emerging from, and recording, our predicament, as there has been in earlier plagues. Figure 2 shows Edvard Munch's "Self-Portrait After the Spanish Flu," and much more on the subject can be found through an internet search for "Drawing Lessons in Time of Plague."

Our reception of any imaginative offering-literature, music, art-is molded by our experiences intermingled with our own imagination. Unsurprising that a pandemic might impel us to have quite a changed tone of appreciation of them. And even objects that have the stubborn staying power as mute inhabitants of the material worldeven they change when viewed in a time of plague. Proust comments in Time Regained, "Certain people, whose minds are prone to mystery, believe that objects retain something of the eyes which have looked at them." I suppose that our gazes in the midst of this pandemic can transform-before our eyes-even the most robust object.

Maybe our sense of community, maybe our idea of justice-and how the mechanism of justice should be protected, and more radically, what all that boils down to meaning-maybe all that will change. Our recognition of the role of government in our common vulnerability is already changing.

Panta rbei-all things change.

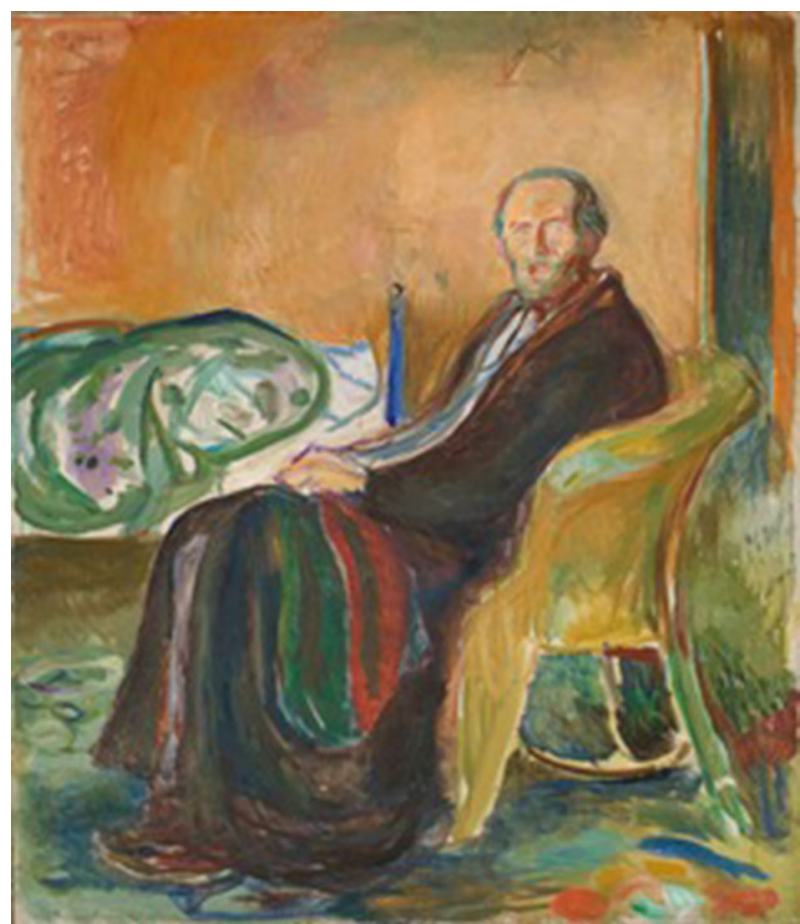

Figure 2. Edvard Munch, "Self-Portrait after the Spanish Flu," 1919. (Courtesy of the National Museum for Art, Architecture and Design, Oslo, Norway.) 
Well, not quite.

I'm guessing-hoping - that all of our interests, and no matter what it is that we devote ourselves to, have core sensibilities, untouchable by external ravages. Those gems of constancy. It could be an interesting exercise, then, to examine what they are, to appreciate how valuable they are to our thoughts, and to our being.

In The Wealth of Nations, Adam Smith picks out what he calls a propensity in human nature: "the propensity to truck, barter, and exchange one thing for another." But then Smith steps back from affirming it as "one of those original principles in human nature."

Seeking more firmly rooted propensities in human nature, isn't there an imperturbable essence, for example in our impulse to storytelling? As Boccaccio proclaims in the "Proem" that launches his hundred tales, this impulse has

altogether or in part, power to draw the mind unto itself and to divert it from troublous thought, at least for some space of time, whereafter, one way or another, either solacement superveneth or else the annoy groweth less. ${ }^{3}$

And even behind this, there is a primal mimetic urge-the germ of any art form according to Aristotle. This is an urge we all have-in some form, even if exercised only in our imagination; recollection itself being the most primitive mimetic act. The manner of expressing our common instinct to re-create and project images or experiences, or emotions, is as varied as human experience, but the very kernel instinct-of mimesis, or re-presentation-remains "an ever-fixed mark" and unwavering in all of us.

And then, mathematical thought. How peculiarly steadfast mathematical concepts are-let alone its truths.

Of course, as with everything we humans do, the way we express our mathematics might evolve.

The vocabulary, the setting, the very attitude toward those activities and people's emotional response to them may vary from generation to generation. Cardano exhorted his sixteenth-century readers to "dismiss mental tortures" so that they could bear to use the square root of -15 in a specific computation, whereas by two centuries or so later, mathematicians, physicists, and engineers would greet complex numbers with delight rather than anguish.

But what about our primal sense of those underlying concepts? No matter how you frame any movement of thought in mathematics, for example constructions as in Euclidean geometry or in algebra or in any mathematical theory, its underlying meaning seems impervious to worldly vicissitudes.

This holds as well for the most elementary constructions; think of the activity of considering twice somethingwhether you label it zweimal or deux fois, or give it no particular label-the fundamental act of conceiving the double of a quantity, be it a number (formulated and denoted however you want to formulate or denote numbers) or be it a geometric entity, has an unswerving intent and meaning. This process of doubling, even though you might dismiss it as extremely simple, is an excellent

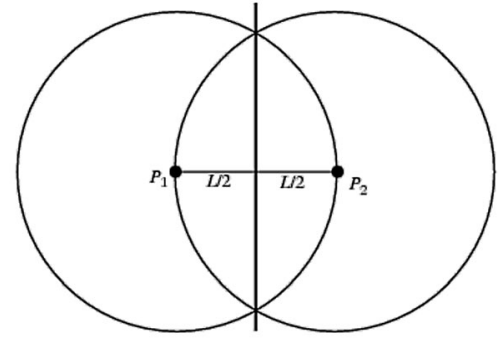

Figure 3. Euclid's construction of the perpendicular bisector of a line segment. (By Eric W. Weisstein, courtesy of MathWorld, a Wolfram Web Resource.)

example of a mathematical step of thought, and it sharesat least for the purpose of this discussion-all the essential qualities of any of the less readily graspable acts of the mathematical imagination.

Or going the other way, consider the process of halving. Euclid begins his journey through the Elements by finding "half" a line segment by performing two swipes of a compass (Figure 3), creating a perpendicular bisector (despite the fact that nowhere in his axiomatic setup is there any hint that two circles can intersect).

Simple constructions even simpler than these-or others that we hardly catalogue as constructions-without even depending on any clear prior structure-lodge in our imagination; they form, in one way or another, what I want to call our common mathematical sensibility. Admittedly, this sensibility is more developed in certain people than in others, but I think there is an imperturbable quality to itand we all have some of it.

As we navigate the world, we can't help putting order (and finding order: patterns, rhythms, symmetries) in our thoughts about the objects, or ideas, that we encounter. That's not yet mathematics. It becomes so only when we make that tiny leap of level and dwell on the order or pattern or rhythm or symmetry as a thing-in-itself separate from the object or idea for which it was, initially in our thoughts, only a property.

The examples I just gave, doubling and halving-these extremely primitive bedrocks of thought-lie before any of the grand constructions of the subject. And earlier than the very idea of proof.

We're certainly lucky to have rigorous mathematical proof. It models and captures the essential quality of any reasoned argument that is careful to make transparent the prior stipulated truths on which that argument rests. How magical it is that the sharp edge of mathematical proof very often achieves universal agreement. But

- setting aside the great mathematical analogies that link different sources of intuition such as geometry and algebra,

- setting aside the various attitudes toward the nature of mathematics, attitudes that carry the labels platonism, or intuitionism, 
- setting aside the history of self-entanglement issues in the foundations of mathematics,

- and even ignoring, for the moment, the weight Kant puts on his grand opening question in the Critique of Pure Reason, "How Is Pure Mathematics Possible," thereby subtly stipulating that Pure Mathematics is, in fact, Possible, ${ }^{4}$

there is, I think, a basic mathematical sensibility residing in all of us, expressed by the many (often unnoticed) expressions of our mathematical instincts. Such instincts, almost indescribable in language, may well be the grounding of what we value in rational thought, instincts (pronoetic, as my son Zeke used to say) that seem to be rooted in times even prior to the emergence of intellect itself. At the very least, this capability, this sensibility, hasn't changed-I'm sure-from the epochs even before the days when the Pythagoreans were investigating triangles. There's a universal firmness to even the most elementary mathematical thought that makes it seem to be untouched by Time. And by Plague. Mathematics is "omnitemporal," to use a latinate word that is one way of translating Edmund Husserl's more gemütlich "Allzeitlich.",

In our current distancing social existence, with schools closed down, and where Zoom classrooms sometimes have the feel of Town Hall meetings and sometimes the feeling of Quaker meetings, these new "feels" of classrooms are modifying how we teach-what it means to teach. There are many wonderful ways to teach-and to learn. ${ }^{6}$

Very close friends of mine, Bob and Ellen Kaplan, have run classes for children, with ages ranging from 4 to 14 , called math circles. ${ }^{7}$ The Kaplans have held these classes for decades, but had them converted to Zoom even prior to the appearance of Covid-19. The manner in which Bob begins a class of four- and five-year-old children is to stride into the classroom-now the screen-and confidently write in large print:

$$
\begin{array}{llllllll}
1 & 2 & 3 & 5 & 6 & 7 & \ldots
\end{array}
$$

By the time the number 7 is inscribed, some child will shout, "But you forgot 4." Bob will strike his forehead with his hand and proclaim, "Oh yes, you're right. Of course there's a number between 3 and 5," as he inserts a 4 in the appropriate spot. And without losing a second will add, "But there's surely no number between 4 and 5." Some child will invariably counter that by offering, "I'm four and a half," at which point Bob's hand will again go to his forehead, as he corrects that second mistake, further revising his increasingly crowded number line. It is in this elegant via negativa approach that by a seemingly neverending series of Bob's mistakes corrected by the children, a great many mathematical concepts are constructed and examined, leading to further questions.

What power of illumination error possesses! Learning from error is one of the many daily delights we all have. Mathematicians, of course, too-what with indirect argument as one systematized embodiment of math "learning from error."

Sometimes, in trying to show that a certain something endowed with specific features doesn't exist, mathematicians, having lived-perhaps for years-with such a nonexistent object, and having established various properties that it would have if it existed, give it a congenial name-even if it has no "local habitation." Such conjecturally nonexistent yet familiar objects become pets-so to speak-destined to be shown to be will-o'-the-wisps.

For example, analytic number theorists talk about something they call the ghost zero, which, if it existed, would carry consequences that we should be aware of; it surely doesn't exist-but we don't know that yet. I would think that all mathematicians have encountered and dwelt with some such object-or perhaps a number of themhaving specific properties (if they existed) but where the important mission is to show nonexistence; that they are indeed ignes fatui. (I lived day and night for a number years with at least one such creature that was-decades laterhappily and finally shown not to exist by Perelman's proof of the three-dimensional Poincaré conjecture.)

How can mathematicians be of help in our current pandemic? Here-as always - there is a crucial distinction between pure and applied mathematics, the latter being of critical importance, a treasure trove of, to use Benjamin Franklin's cherished humble-seeming phrase, useful knowledge.

Applied mathematicians have been pressed into service; how grateful we all are for the precision of immunological and epidemiological studies - the collecting, sorting, classifying, and interpreting of data. And for the formulation, and calibration, of models that help in interpreting what the data want to tell us about what has happened in the past and what we can expect for the future.

So then, how can pure mathematicians be of help? Besides, of course, teaching multivariable calculus and probability theory to a future generation of epidemiologists and practitioners, and just homeschooling children or grandchildren and keeping in contact with students; usually, necessarily, Zoom contact.

As for this new Zoom epoch, there are many in our mathematical community-including undergraduate math majors, ${ }^{8}$ graduate students, and professors-who are taking the initiative to make use of this moment when math classes are zooming all over the world to design fundamental online techniques to accommodate this moment, where standard courses may have international range-as

\footnotetext{
${ }^{4}$ And the consequences he draws from this.

${ }^{5}$ Which is itself resonant with St. Augustine's discussion in the Confessions about the perplexity one has in understanding God's relation to time.

'If I had had a chance to nudge Meno to sharpen the question that kickstarts the Platonic dialogue that carries his name, I'd have suggested he ask, "How can I learn virtue?"

${ }^{7}$ Their math circles have now propagated all over the world: see https://www.globalmathcircle.com.

${ }^{8}$ See the July 1, 2020, Harvard Crimson article by Leo Alcock, a sophomore math major at Harvard, "What I Learned from My First Lockdown."
} 
does Ravi Vakil's (current online summer) algebraic geometry course (which has over 1600 signups around the world). ${ }^{9}$

But theoretical mathematicians also can just try to be close and engaged listeners of the reports coming from their colleagues who are at work in applied directions. I personally intend to learn a bit about the mechanisms of forecasting during this pandemic to make up for my total lack of knowledge or experience about the handling of data in any form (and for any purpose).

Extremely good expositions are available that assume absolutely nothing at all in the way of background knowledge and rather rapidly get you (even if you are an extreme outsider) to be able to-and to want to--dig into relevant data, such as data regarding the evolution of particular strains of Covid-19.

One such exposition, mentioned to me by the statistician Susan Holmes, is a YouTube presentation by Pleuni Pennings, a researcher at San Francisco State University who studies the evolution of viruses, but not Covid-19. ${ }^{10}$ In her presentation, Pennings shows how to work with genetic evolutionary trees of Covid-19 developed by Trevor Bedford, an evolutionary biologist who is an expert in virus tracking, ${ }^{11}$ and the team at the Seattle Flu Study who sequenced the genome of Covid-19. ${ }^{12}$ She explains how to use that online database to trace a mutation at a point of the genetic code of the virus as it travels its way through Washington State and trace it back to antecedents in China.

When it comes to reading about models and forecasts based on models, I feel that I, as an outsider, need more guidance to understand them than is often available.

For example, in forecasts that give, say, an estimate (within a 95\% confidence interval) of the range of uncertainty, ${ }^{13}$ it might (if both the model used for forecasting and the circumstances regarding the data collected haven't changed in any significant way in the recent past) be useful to nonprofessional readers like me if easy access to past forecasts were also offered, i.e., providing information on how well, in the forecasts given in days or weeks past, the model's projected range of uncertainty encompassed the actual data.

And contemporary models are rather complex-not as elementary as the first mathematical models in the modern era, like the one outlined in Thomas Malthus's 1798 An Essay on the Principle of Population. Malthus's model has two transparent variables, and none hidden. These are governed by his two initial postulates:

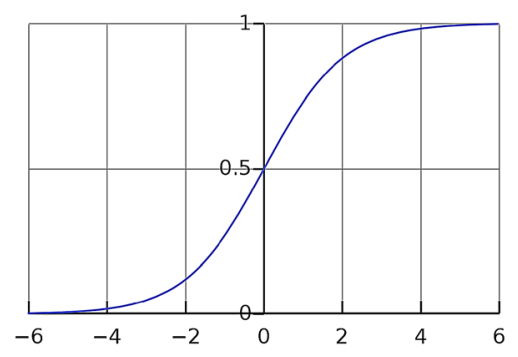

Figure 4. The logistic curve. (Reproduced from the Wikipedia article "Sigmoid Function," in the public domain.)

- First, that food is necessary to the existence of man.

- Secondly, that the passion between the sexes is necessary and will remain nearly in its present state.

The second postulate would have population increasing exponentially, while the first is what tempers that exponential growth, leading to the proliferation of sigmoid curves (Figure 4) that dominate the subject-in today's parlance, it is the agent that "flattens the curve." "Population, when unchecked," writes Malthus,

increases in a geometrical ratio. Subsistence increases only in an arithmetical ratio. A slight acquaintance with numbers will shew the immensity of the first power in comparison of the second.

Modern research is nothing as simple as that; it involves astute manipulation of the models, curve-fitting-using the various parameters allowed by a host of hidden variables, combining, with an experienced eye, data (of different sample sizes) from different sources (with different variances and margins of error). ${ }^{14}$

As for "different variances," take the simple parameter known as $R_{0}$, the basic reproductive number of the virus, characterizing the average number of secondary cases generated by each primary case. Thus if $R_{0}$ were equal to 2 , that would mean that on average, each of us, when infected, infects two others; this would be bad news even though it couldn't go on that way forever.

This single number $R_{0}$ is more or less informative depending on how homogeneous the population is. If we average over conglomerates of different populations of

\footnotetext{
${ }^{9}$ See the Open Online Education Project (OOEP) at ooep.org; its mission is to expand and improve online education and to extend the breadth and depth of free course resources worldwide. This project was inspired by MIT's decades-old OpenCourseWare.

${ }^{10}$ Available at https://www.youtube.com/watch?v=pgOwkFRBRt8.

${ }^{11}$ To work with his team's evolutionary tree, see https://nextstrain.org/ncov/global.

${ }^{12}$ See seattleflu.org.

${ }^{13}$ As in, for example, https://covid19.healthdata.org/united-states-of-america.

${ }^{14}$ Today, for example, NPR reported on the work of Nicholas Reich, a biostatistician at the University of Massachusetts, Amherst, who with his colleagues has developed a method to merge the diverse models of a disease's progression into one "ensemble" projection:
}

It's a sort of portal through which the scientists behind each COVID-19 model can communicate key details about their methodology and results, so that, as Reich explains, "all of these forecasts can be represented in a single standardized way. And this makes it really easy to make apples-to-apples comparisons between these models." 
different age levels, with different levels of susceptibility, and-more to the point-different practices that produce different levels of exposure to individuals to get a single "average number" $R_{0}$, it would be far less useful than if one devised a hierarchy of separate analyses each focused on a different segment of the population, these subpopulations representing more internal homogeneity, and perhaps significantly smaller variance in the data. One would end up with a hierarchy of $R_{0}$ values that would convey real information, a worthy guide for possible action, or prediction, more informative than just a single overall average number. This is suggested in the paper "Modeling the Heterogeneity in COVID-19's Reproductive Number and Its Impact on Predictive Scenarios," by Claire Donnat and Susan Holmes. ${ }^{15}$

Whether or not we understand models, they are all around us. Models organize our life via machine-learned stratagems; they tell us how to proceed in one activity or another. Some of these models trigger self-reinforcing feedback loops that tell us to do more of a certain activity if we have simply already done lots of it. A troubling example of this can be found in the predictive policing software PredPol, ${ }^{16}$ which even according to the company that produced it is based on earthquake prediction, and-according to a statistician (Kristian Lum) who has looked at it-is "just a moving average," i.e., it takes an average of where arrests have already occurred and tells police to go back there. But in the words of the company that produced it, it is

based on nearly seven years of detailed academic research into the causes of crime pattern formation ... the mathematics looks complicated-and it is complicated for normal mortal humans-but the behaviors upon which the math is based are very understandable.

This alone is troubling talk, vaunting a level of incomprehensibility of the mathematics of their model - a model that encourages police to look for petty crime that may go unnoticed in other neighborhoods.

Happily, there are movements pressing for real reform: to have the police fulfill their function primarily as guardians rather than warriors. ${ }^{17}$ And perhaps inspired by this time of plague, and even more by protests resounding internationally, we are in the midst of a call for fundamental reevaluation of the way we treat, or-to put it one step removed-society treats, segments of humanity.

Times of plague are times of all kinds of reevaluation. There is a legend that during the cholera epidemic of 1848 , Rabbi Israel Salanter, the religious and ethical leader of the Jewish community in Vilna, publicly called for his community to eat, and not to fast, on the solemn fast day of Yom Kippur. That was so his community would not be made more vulnerable to the plague by a day of fasting. ${ }^{18}$ The pinnacle of holy observance stands back for the plague.

We have no idea how things will evolve, how we ourselves will be altered. In such a time, we can at least be thankful for the shared ideas that ground us, ideas that unite us, and for the unwavering solidity of certain keystones of thought. ${ }^{19}$

And we can try to work-in whatever way we cantoward a healthier (and more just!) global community, looking for the day when the pandemic forecasts we currently face become hindcasts, and this time of plague a memory.

\section{ACKNOWLEDGMENTS}

An excerpt of this article (with some further reflections) entitled "The Consolation of Math in Plague Time" will appear in the volume Math in the Time of Corona, edited by Elizabeth Loew, to be published by Springer.

\author{
Barry Mazur \\ Department of Mathematics \\ Harvard University \\ One Oxford Street \\ Cambridge, MA 02138 \\ USA \\ e-mail: mazur@math.harvard.edu
}

Publisher's Note Springer Nature remains neutral with regard to jurisdictional claims in published maps and institutional affiliations.

\footnotetext{
${ }^{15}$ Available at https://arxiv.org/pdf/2004.05272.pdf. The authors deal with nineteen geographical groups to gauge the amount of variability shown in the reproductive number:

- the six countries reporting the highest numbers for the epidemic in Europe (Italy, Spain, France, Germany, the United Kingdom, and Switzerland),

- seven groups in Asia (Hong Kong, the Chinese provinces of Guizhou and Hubei, Singapore, Thailand, as well as Japan and South Korea),

- Iran,

- the United States as a whole, as well as the states of California, Washington, and New York.

${ }^{16}$ See "Dozens of Cities Have Secretly Experimented with Predictive Policing Software," by Caroline Haskins, Motherboard, 2019.

${ }^{17} \mathrm{See}$, for example, https://www.policeone.com/research/articles/is-there-any-evidence-concerning-the-warriorguardian-debate-in-policing-y9hPZYjiBHXrYOcB/.

${ }^{18}$ The primary school I attended was Yeshiva Israel Salanter, in the Bronx, which Rabbi Salanter's humane mussar sentiments pervaded-in the midst of precise, demanding, and all-encompassing religious ritual. Salanter's mantra—along with the standard "love thy neighbor" —was the equally exacting "my neighbor's material needs are my own spiritual needs." My schooldays at Salanter had a transcendental electricity that I am very thankful for and continue to be puzzled by.

${ }^{19}$ Even the simplest mathematical gems, such as the tetrahedron, cube, octahedron, dodecahedron, and icosahedron that Euclid encountered at the end of his tour of the Elements.
} 